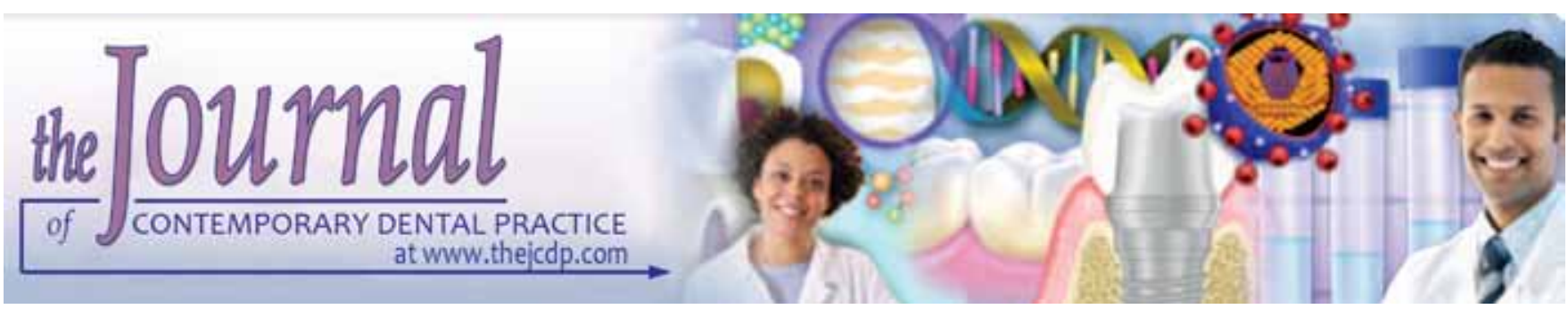

\title{
Comparative Evaluation of Two Final Irrigation Techniques for the Removal of Precipitate Formed by the Interaction between Sodium Hypochlorite and Chlorhexidine
}

${ }^{1}$ Malasiddappa Metri, ${ }^{2}$ Swaroop Hegde, ${ }^{3} \mathrm{~K}$ Dinesh, ${ }^{4} \mathrm{HN}$ Indiresha, ${ }^{5}$ Shruthi Nagaraj, ${ }^{6}$ Shilpa H Bhandi

\begin{abstract}
Aim: To evaluate the effectiveness of two final irrigation techniques for the removal of precipitate formed by the interaction between sodium hypochlorite $(\mathrm{NaOCl})$ and chlorhexidine $(\mathrm{CHX})$.

Materials and methods: Sixty freshly extracted human maxillary incisor teeth were taken and randomly divided into three groups, containing 20 teeth each. Group 1 (control group), were irrigated with $5 \mathrm{ml}$ of $2.5 \% \mathrm{NaOCl}$ and a final flush with $5 \mathrm{ml}$ of $2 \%$ chlorhexidine. Group 2 were irrigated with $5 \mathrm{ml}$ of $2.5 \% \mathrm{NaOCl}$ and $5 \mathrm{ml}$ of $2 \%$ chlorhexidine followed by $5 \mathrm{ml}$ of saline and agitated with F-files. Group 3 were irrigated with $5 \mathrm{ml}$ of $2.5 \% \mathrm{NaOCl}$ and $5 \mathrm{ml}$ of $2 \%$ chlorhexidine followed by $5 \mathrm{ml}$ of $15 \%$ citric acid and passively agitated with ultrasonics. A thin longitudinal groove was made along the buccal and lingual aspect of the root using diamond disks and split with chisel and mallet. Both halves of the split tooth will be examined under stereomicroscope. Results were tabulated and analyzed statistically using analysis of variance (ANOVA) and MannWhitney U test.
\end{abstract}

Result: There was a significant difference between the mean values $(p<0.05)$ in groups 2 and 3 compared to group 1 at each level.

Conclusion: Passive ultrasonic irrigation is more effective than the F-file agitation technique to remove the precipitate at all three levels measured.

Clinical significance: Combination of sodium hypochlorite and chlorhexidine irrigation protocol has been practiced since from many years to achieve good results. However, it has adverse

${ }^{1}$ Department of Conservative Dentistry and Endodontics, PMNM Dental College and Hospital, Bagalkot, Karnataka, India

${ }^{2-6}$ Department of Conservative Dentistry and Endodontics Faculty of Dental Sciences, MS Ramaiah University of Applied Sciences, Bengaluru, Karnataka, India

Corresponding Author: Malasiddappa Metri, Senior Lecturer Department of Conservative Dentistry and Endodontics, PMNM Dental College and Hospital, Bagalkot-587101, Karnataka, India Phone: 91 9591796941, e-mail: msmetri01@gmail.com effect in the form of precipitate and which is considered to be a carcinogenic in nature, hence this precipitate should be removed.

Keywords: Chlorhexidine, Interaction, Parachloroaniline, Sodium hypochlorite.

How to cite this article: Metri M, Hegde S, Dinesh K, Indiresha $\mathrm{HN}$, Nagaraj S, Bhandi SH. Comparative Evaluation of Two Final Irrigation Techniques for the Removal of Precipitate Formed by the Interaction between Sodium Hypochlorite and Chlorhexidine. J Contemp Dent Pract 2015;16(11):850-853.

Source of support: Nil

Conflict of interest: None

\section{INTRODUCTION}

One of the most important objectives of endodontic therapy is the complete elimination of microorganisms from the root canal system. Although chemomechanical preparation of the root canals is able to reduce the number of bacteria, complete canal disinfection is difficult because of the complexity of the internal root canal anatomy. Therefore, various antimicrobial agents, such as sodium hypochlorite $(\mathrm{NaOCl})$ are used as irrigants during the canal preparation and as a final flush to minimize the necrotic tissue and bacteria. ${ }^{1}$

Sodium hypochlorite in a concentration range of 0.5 to $5.25 \%$ possesses many important properties including the ability to be an effective organic solvent and antimicrobial agent. However, in low concentrations, it is ineffective against specific microorganisms, and in high concentrations has low biocompatibility causing periapical inflammation. ${ }^{2}$

Chlorhexidine (CHX) is a broad-spectrum antimicrobial agent that disrupts the membranes of microbes. It has been suggested for use as an irrigant and intracanal medicament because of its lower toxicity when compared 
with $\mathrm{NaOCl}$. Chlorhexidine has comparable antibacterial efficacy as $\mathrm{NaOCl}$ and has the advantage of having substantivity. ${ }^{3}$ However, $\mathrm{CHX}$ lacks the tissue dissolution capabilities of $\mathrm{NaOCl}$.

A combination of $\mathrm{NaOCl}$ and $\mathrm{CHX}$ has been advocated to enhance their antimicrobial properties. A concern about this irrigation regimen is that with the presence of $\mathrm{NaOCl}$ in the root canal, irrigation with $\mathrm{CHX}$ produces an orange-brown precipitate known as parachloroaniline. ${ }^{4}$ The precipitate occludes the dentinal tubules and may compromise the seal of the obturated root canal. The precipitate is cytotoxic, leading to the concern of it leaching out of the canal, and hence has to be removed. ${ }^{4,5}$ Hence, this ex vivo study was undertaken to evaluate the efficacy of two final irrigation techniques namely passive ultrasonic irrigation and agitation of irrigant with F-file to remove the precipitate formed by the interaction between sodium hypochlorite and chlorhexidine.

\section{MATERIALS AND METHODS}

Sixty freshly extracted human maxillary incisor teeth were taken for this study. The teeth were decoronated $1 \mathrm{~mm}$ below the cementoenamel junction using diamond disk at slow speed. The working length was determined with \#15 K-file introduced into the canal until the tip of the file was visible at the apical foramen and $1 \mathrm{~mm}$ subtracted from this length.

The root ends of the prepared teeth were inserted into softened impression compound and allowed to set. This prevented extrusion of the irrigants out of the apex and allowed ease of handling during instrumentation. Canals were instrumented with stainless steel K-files to \#60 at the apex in a crown-down technique.

During instrumentation, the canals were irrigated between each instrument change with $1 \mathrm{ml}$ of $2.5 \%$ $\mathrm{NaOCl}, 3 \mathrm{~mm}$ from the working length, using a 26-gauge hypodermic needle. Once after the cleaning and shaping procedure, all the specimens were irrigated with a $5 \mathrm{ml}$ of $17 \%$ EDTA to remove the smear layer. Followed by all the specimens were randomly divided into three groups of 20 each: Group 1 (control group), canals were irrigated with $5 \mathrm{ml}$ of $2.5 \%$ of $\mathrm{NaOCl}$, followed by a final irrigation with $5 \mathrm{ml}$ of $2 \%$ chlorhexidine; group 2, canals were irrigated with $5 \mathrm{ml}$ of $2.5 \%$ of $\mathrm{NaOCl}$, followed by $5 \mathrm{ml}$ of $2 \%$ chlorhexidine. After which the canals were flushed with $5 \mathrm{ml}$ of saline and agitated with F-files (Plastic Endo, LLC, Buffalo Grove, IL,USA) attached to slow speed contra angle hand piece set at $600 \mathrm{rpm}$; group 3, canals were irrigated with $5 \mathrm{ml}$ of $2.5 \%$ of $\mathrm{NaOCl}$, followed by $5 \mathrm{ml}$ of $2 \%$ chlorhexidine. After which the canals were flushed with $10 \mathrm{ml}$ of $15 \%$ citric acid followed by agitation with passive ultrasonic with tip No. E4 (NSK).
A thin longitudinal slot was made along the buccal and lingual aspect of the roots using diamond disks, making sure to avoid perforation into the canal. Using a chisel and mallet, the roots were split longitudinally. Both halves of the split tooth were examined by stereomicroscopy (OLYMPUS 5010) at 40 and 100× magnifications.

The spilt samples of each group were examined at the coronal, middle, and apical third levels. The thickness of the precipitate was measured from its outer surface to the inner dentinal wall at a uniplanar level using ProgRes computer software (JENOPTIK, Germany).

The results were tabulated and analyzed statistically using analysis of variance (ANOVA) and Mann-Whitney $\mathrm{U}$ test, the results obtained were statistically significant $(\mathrm{p}<0.05)$. All calculations were made through the programs 19 Statistical Package for the Social Science (SPSS).

\section{RESULTS}

The stereomicroscopic examination revealed that specimens in the group 1 where no final irrigation protocol was followed showed thick orange-brown precipitate deposited all along the canal wall. Table 1 shows there was no significant difference in the thickness of the precipitate formed at the coronal, middle and apical thirds on both the halves hence, the values were merged ( $p>0.05$ ). Table 2 shows comparison between groups 2 and 3, graph indicates that group 3 (Passive Ultrasonic) scored lowest mean value.

Table 1: Comparison of mean score between the two halves at coronal, middle and apical thirds

\begin{tabular}{|c|c|c|c|c|c|c|}
\hline Groups & & Patients & Mean & $S D$ & $N$ & $p$-value \\
\hline \multirow[t]{6}{*}{1} & Coronal & 1st Half & 635.709 & 43.388 & 20 & 0.922 \\
\hline & & 2nd Half & 634.295 & 47.625 & 20 & \\
\hline & Middle & 1st Half & 526.823 & 38.954 & 20 & 0.867 \\
\hline & & 2nd Half & 529.226 & 50.454 & 20 & \\
\hline & Apical & 1st Half & 229.784 & 20.993 & 20 & 0.552 \\
\hline & & 2nd Half & 226.146 & 17.155 & 20 & \\
\hline \multirow[t]{6}{*}{2} & Coronal & 1st Half & 3.513 & 1.162 & 20 & 0.692 \\
\hline & & 2nd Half & 3.362 & 1.222 & 20 & \\
\hline & Middle & 1st Half & 3.684 & 1.431 & 20 & 0.783 \\
\hline & & 2nd Half & 3.562 & 1.378 & 20 & \\
\hline & Apical & 1st Half & 141.938 & 34.807 & 20 & 0.671 \\
\hline & & 2nd Half & 146.602 & 34.195 & 20 & \\
\hline \multirow[t]{6}{*}{3} & Coronal & 1st Half & 0.830 & 0.559 & 20 & 0.704 \\
\hline & & 2nd Half & 0.895 & 0.516 & 20 & \\
\hline & Middle & 1st Half & 1.070 & 0.668 & 20 & 0.657 \\
\hline & & 2nd Half & 1.163 & 0.647 & 20 & \\
\hline & Apical & 1st Half & 38.723 & 24.720 & 20 & 0.410 \\
\hline & & 2nd Half & 45.283 & 25.119 & 20 & \\
\hline
\end{tabular}


Table 2: Comparison of mean score between groups 2 and 3 groups at coronal, middle and apical thirds

\begin{tabular}{llll}
\hline Groups & Comparison & Mann-Whitney U test & p-value \\
\hline Coronal & group 2 vs group 3 & 132.87 & 0.00 \\
Middle & group 2 vs group 3 & 99.02 & 0.00 \\
Apical & group 2 vs group 3 & 83.01 & 0.002 \\
\hline
\end{tabular}

\section{DISCUSSION}

It is well established that biomechanical cleaning and shaping of the root canal system, using files and antibacterial irrigants, reduces the bacterial load. A suggested clinical protocol for treating the dentin before root filling consists of irrigation with $\mathrm{NaOCl}$ to dissolve the organic components, irrigation with EDTA to eliminate the smear layer and irrigation with CHX to impart substantive antibacterial activity. Although such combination of irrigants may enhance their antimicrobial properties, possible chemical interactions among the irrigants have to be considered. ${ }^{4}$

The formation of the precipitate could be explained by the acid-base reaction between $\mathrm{NaOCl}$ and $\mathrm{CHX}$. Chlorhexidine is a dicationic acid ( $\mathrm{pH} 5.5-6.0)$ that has the ability to donate protons. Sodium hypochlorite is alkaline being able to accept protons from the dicationic CHX. This proton exchange results in the formation of a neutral and insoluble substance referred to as the precipitate and this precipitate contains parachloroaniline (PCA). ${ }^{2}$ When mixing $2 \% \mathrm{CHX}$ with various dilutions of $\mathrm{NaOCl}$, it was shown that the solution color changes directly according to the concentration of sodium hypochlorite, ranging from peach to dark brown as the concentration increases from 0.023 to $6 \%$. The lowest concentration of $\mathrm{NaOCl}$ to induce a precipitate was $0.19 \% .6$

In the present study, the F-file was found to be effective in removing the precipitate which could be appreciated at all the three levels measured. The unique file design of F-file with its coating of diamond abrasives into a non-toxic polymer enabled the mechanical agitation of the irrigant in the canal ${ }^{7}$ thereby facilitating removal of precipitate.

Passive ultrasonic irrigation performed better in the removal of precipitate than the plastic F-file at all the three levels measured. Passive ultrasonic irrigation performed better than the F-file probably because of the high volume and velocity of the irrigant delivered. Previous studies have proven that passive ultrasonic when used with $3 \%$ $\mathrm{NaOCl}$ is an effective technique in removing debris and smear layer from the root canals. ${ }^{8-11}$ In accordance with the previous study ${ }^{9}$ shown that the use of $15 \%$ citric acid as the irrigant in our study could have further helped in removing the precipitate because of its demineralizing capacity. It also has biocompatibility superior to $\mathrm{NaOCl}^{6}$ These two features in group 3 facilitated its superior performance.

Our study confirmed the formation of an orange brown precipitate following irrigation with $2.5 \% \mathrm{NaOCl}$ and $2 \%$ chlorhexidine. Both the experimental techniques using F-file and passive ultrasonic irrigation proved effective in reducing the precipitate formed at coronal, middle and apical third of the canals. In the present study, results have shown that both the techniques that were agitation with F-file and passive ultrasonic irrigation failed to remove the precipitate from the apical third from all the tested specimens. This could be due to the apical third having a complex anatomy ${ }^{9}$ and numerous ramifications. New and advanced techniques that help in complete removal of parachloroaniline precipitate should be devised and tested.

\section{CONCLUSION}

As per the limitations of the study, it can be concluded that final irrigation with F-file or passive ultrasonic irrigation can be considered as effective alternate techniques to reduce/remove the PCA precipitate. Passive ultrasonic irrigation is more effective than the F-file agitation technique to remove the precipitate at all three levels measured.

\section{REFERENCES}

1. Krishnamurthy S, Sudhakaran S. Evaluation and prevention of the precipitate formed on interaction between sodium hypochlorite and chlorhexidine. J Endod 2010;36(7): 1154-1157.

2. Akisue E, Tomita VS, Gavini G, de Figueiredo JAP. Effect of the combination of sodium hypochlorite and chlorhexidine on dentinal permeability and scanning electron microscopy precipitate observation. J Endod 2010;36(5):847-850.

3. Basrani BR, Manek S, Mathers D, Fillery E, Sodhi RNS. Determination of 4-Chloroaniline and its derivatives formed in the interaction of sodium hypochlorite and chlorhexidine by using gas chromatography. J Endod 2010;36(2):312-314.

4. Bui TB, Baumgartner JC, Mitchell JC. Evaluation of the interaction between sodium hypochlorite and chlorhexidine gluconate and its effect on root dentin. J Endod 2008;34(2): 181-185.

5. Basrani BR, Manek S, Sodhi RNS, Fillery E, Manzur A. Interaction between sodium hypochlorite and chlorhexidine gluconate. J Endod 2007;33(8):966-969.

6. Rossi-Fedele G, Dogramaci EJ, Guastalli AR, de Figueiredo JAP. Antagonistic interactions between sodium hypochlorite, chlorhexidine, EDTA, and citric acid. J Endod 2012;38(4): 426-431.

7. Bahcall J, Olsen FK. Clinical introduction of a plastic rotary endodontic finishing file. Endod Prac 2007;10:17-20. 
8. Garg G, Talwar S. Comparison of the efficacy of 'F-File' with sonic and ultrasonic debridement to remove artificially placed dentine debris from human root canals: an in vitro study. IES 2010;22(1):39-47.

9. Abou-Rass M, Piccinino MV. The effectiveness of four clinical irrigation methods on the removal of root canal debris. Oral Surg 1982;54(3):323-328.

10. Bhuva B, Patel S, Wilson R, Niazi S, Beighton D, Mannocci F. The effectiveness of passive ultrasonic irrigation on intra- radicular enterococcus faecalis biofilms in extracted singlerooted human teeth. Int Endod J 2010;43:241-250.

11. Dhingra A, Mangat P, Miglani A, Kalkhande S, Bhullar HK. To evaluate the effect of two passive ultrasonic irrigation methods on removal of dentin debris from root canal systems using computational fluid dynamics study model. Int J Contemp Dent Med Rev, Vol 2014, Article ID: 011214, 2014. doi:10.15713/ins.ijcdmr.20 